\title{
Design and Simulation of Single-Phase Five-Level Symmetrical Cascaded H-Bridge Multilevel Inverter with Reduces Number of Switches
}

\section{Adem $Y^{*}$}

Department of Electrical and Electronics Engineering, University of Agriculture, Makurdi, Nigeria

\begin{abstract}
Multilevel inverter is an effective and practical solution for increasing power demand and reducing harmonics of ac waveforms. Such inverters synthesize a desired output voltage from several levels of dc voltages as inputs. This paper analyzes the performance of five level cascaded $\mathrm{H}$-bridge multilevel inverter with reduce number of power switches. Further by reducing switches and increasing level will reduce filter cost \& harmonic content. 5- Level cascaded $\mathrm{H}$-bridge asymmetrical multilevel inverter topology requires 8 switches but in this new multilevel inverter it requires 6 switches in which same multilevel is obtained. Invariably switching losses and cost also reduced. In this paper only multilevel inverter circuitry will be studied. The performance has been analyzed by the MATLAB/Simulink.
\end{abstract}

Keywords: Cascaded multilevel inverter; SPWM; APOD; PD; POD; THD

\section{Introduction}

Basically, inverter is electrical devices that convert direct current (dc) input voltage to a symmetrical alternating current (ac) output voltage of desired magnitude and frequency. The output voltage could be fixed or variable at a fixed or variable frequency.

A variable output voltage can be obtained by varying the input $\mathrm{dc}$ voltage and maintain the gain of the inverter (ratio of the ac output voltage to the dc input voltage) constant.

Conversely, if the dc input voltage is fixed and is not controllable, a variable output voltage can be obtained by varying the gain of the inverter which is normally accompanied by pulse width modulator within the inverter [1]. The waveform of practical inverter are nonsinusoidal and contain some harmonic. Demerits of this inverter are less efficiency, high cost and high switching losses. To overcome these demerits lead to what is called multilevel inverters. This multilevel inverter does the same work as inverter, but on high power applications. This multilevel inverter is an electrical device that is capable of producing different voltage levels. The term multilevel inverter began with three levels converter. The multilevel converter has been introduced since 1975. The cascade H-bridge multilevel inverters was first suggested in 1975 (M. Kavita 2012) [2]. In past years multilevel inverters are used in high power and high voltage applications. Multilevel inverter output voltage produce a staircase output waveform, this waveform look like a sinusoidal waveform. The $\mathrm{mLl}$ output voltage having less number of harmonics as compared to the conventional bipolar inverter output voltage. If the MLI output increase to $\mathrm{N}$ level, the harmonics reduced to the output voltage value to zero.

Multilevel inverters have several advantages as compared to conventional bipolar inverter in the following way.

1. Capability to operate at high voltage with lower $\mathrm{dv} / \mathrm{dt}$ per switching.

2. High level efficiency.

3. Low electromagnetic interferences.

4. High magnitude sinusoidal voltage with extremely low distortion at fundamental frequency can be produced at the output with the help of MLI by connecting sufficient number of $\mathrm{dc}$ at input side.

The multilevel inverter includes an array of power semiconductors and capacitor voltage sources, the output of which generate voltages with stepped waveforms (F.Z. Peng 2003) [3,4]. The commutation of the switches permits the addition of the capacitor voltages, which reach high voltage at the output, while the power semiconductors must withstand only reduced voltages. However, if the number of levels is increases, the number of components required is more, this results into reduction of overall reliability and efficiency of power converter. On the other hand, solution with a low number of levels either need a rather large and expensive LC filter to limit the motor winding insulation stress or can only be used with motors that do withstand such stress. There are three main types of Multilevel Inverter. These are Diode clamped, Flying capacitor and Cascaded H-bridge Multilevel Inverter A $\mathrm{m}$ o n g these three, cascaded $\mathrm{H}$-bridges multilevel has a modular structure and require least number of components as compared to diode-clamped and flying capacitor multilevel inverter, and as a result of this, it is widely used for many applications in electrical engineering [5].

From Figure 1 above, dc input voltage is the source of dc power devices, multilevel inverter ( $\mathrm{n}$-level) changes dc voltage to ac voltage and gating signal control system generates the pulse that control the switching pattern of the H-bridge MOSFET switches [6-9].

All researches work that has gone on inverter circuit configuration mainly in reducing the switches at higher voltage levels, by reducing switches and increasing voltage levels will reduce filter cost and harmonic content. Five-levels CHB MLI topology required Eight switches and two separate dc sources, but to reduce switching loss and cost, six switches required in which the same MLI output voltage is obtained. These CHB MLI with six switches and two batteries will improve output waveform and reduce total harmonic distortion. The circuit diagram of CHB MLI with six switches and two separate dc sources and its switching states

${ }^{*}$ Corresponding author: Adem Y, Department of Electrical and Electronics Engineering, University of Agriculture, Makurdi, Nigeria, Tel: +234 811175 3334; E-mail: yakadng@gmail.com

Received October 10, 2018; Accepted November 02, 2018; Published November 09, 2018

Citation: Adem Y (2018) Design and Simulation of Single-Phase Five-Level Symmetrical Cascaded H-Bridge Multilevel Inverter With Reduces Number of Switches. J Electr Electron Syst 7: 281. doi: 10.4172/2332-0796.1000281

Copyright: $\odot 2018$ Adem Y. This is an open-access article distributed under the terms of the Creative Commons Attribution License, which permits unrestricted use, distribution, and reproduction in any medium, provided the original author and source are credited. 
is shown below Table 1. The core aim of this topology is to reduce number of switches. This 5-level inverter carries 6 switches in two legs, and three switches in each leg. The switches are named as S1, S2, S3, S4, S5 and S6. S1, S2, S3 are placed in first leg and S4, S5, S6 are placed in second leg as shown in Figure 2 below [10-13].

\section{Switching Schemes with Operations}

- $\quad$ For $+2 \mathrm{Vdc}$, switch S2, S4 and S6 are switched ON for getting maximum voltage (Figure 3 )

- For $+1 \mathrm{Vdc}$, switch S2, S3 and S4 are switched ON for next priority level of voltage (Figure 4)

- For zero output voltage, switches S4, S5 and S6 are switched ON (Figure 5)

- For negative $(-2 \mathrm{Vdc})$ voltage switch $\mathrm{S} 1, \mathrm{~S} 3$ and $\mathrm{S} 5$ are switched ON (Figure 6)

- For negative $(-1 \mathrm{Vdc})$ voltage, switch $\mathrm{S} 1, \mathrm{~S} 2$ and $\mathrm{S} 6$ are switched ON (Figure 7)

- Pulses for 5-level symmetric CHB MLI (Figure 8)

\section{Simulation Results}

In this paper MATLAB, PROTEUS is used. Proteus is a real time software tool which is implemented before performing hardware. In MATLAB the five level inverter circuit is simulated and results of output voltage and THD is shown below Figure 9.

The GUI plots are used for the Fast Fourier Transforms (FFT) analysis to determine the Total Harmonic content (THD) Figures 10-12.

The simulation of 5-level is carried out in MATLAB SIMILINK. Total Harmonic distortion calculated, and is $23.20 \%$. MOSFET are used in this design which has high voltage and current carrying capability. A gate driver circuit is to be used for boosting the pulses from a microcontroller PIC16F877A and is used for generating required pulses [13-17].

\begin{tabular}{|c|c|c|c|c|c|c|c|}
\hline \multirow{2}{*}{ S/no } & \multicolumn{6}{|c|}{ Switching sequences } & \multirow{2}{*}{ Voltage levels } \\
\hline & S1 & S2 & S3 & S4 & S5 & S6 & \\
\hline 1 & 0 & 1 & 0 & 1 & 0 & 1 & $+2 \mathrm{Vdc}$ \\
\hline 2 & 0 & 0 & 1 & 1 & 1 & 0 & $+1 \mathrm{Vdc}$ \\
\hline 3 & 0 & 0 & 0 & 1 & 1 & 1 & $0 \mathrm{Vdc}$ \\
\hline 4 & 1 & 1 & 0 & 0 & 0 & 1 & $-1 \mathrm{Vdc}$ \\
\hline 5 & 1 & 0 & 1 & 0 & 1 & 0 & $-2 \mathrm{Vdc}$ \\
\hline
\end{tabular}

Note: 1 indicates that switch is ON state,

0 indicates that switch is OFF state

Table 1: Switching states of modified 7-levels CHB MLI.

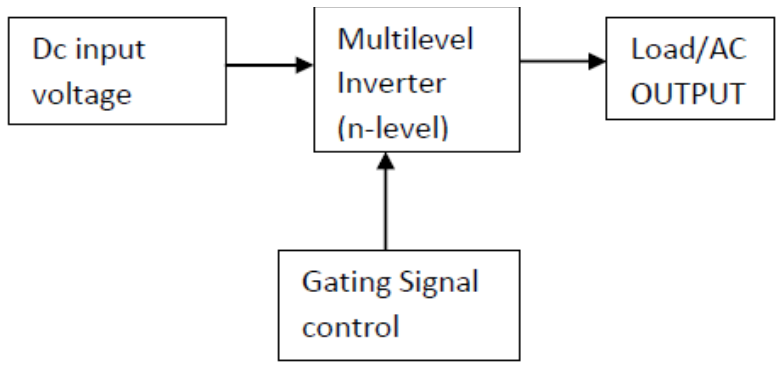

Figure 1: Multi-user Distributed Massive MIMO transceiver model system.

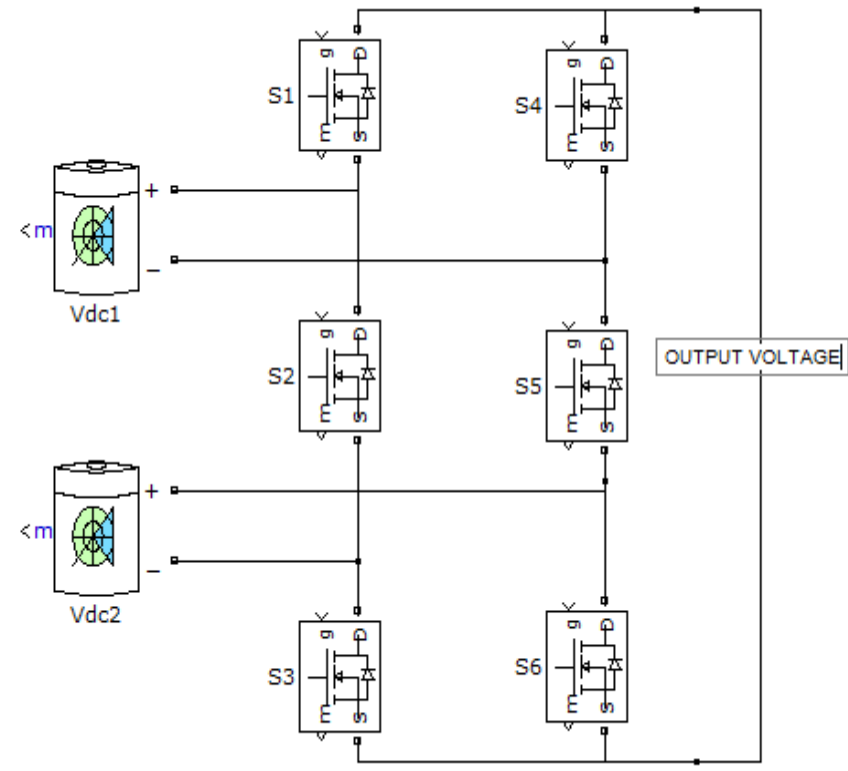

Figure 2: Circuit diagram of 5-level CHB MLI with reduced switches \& dc sources.

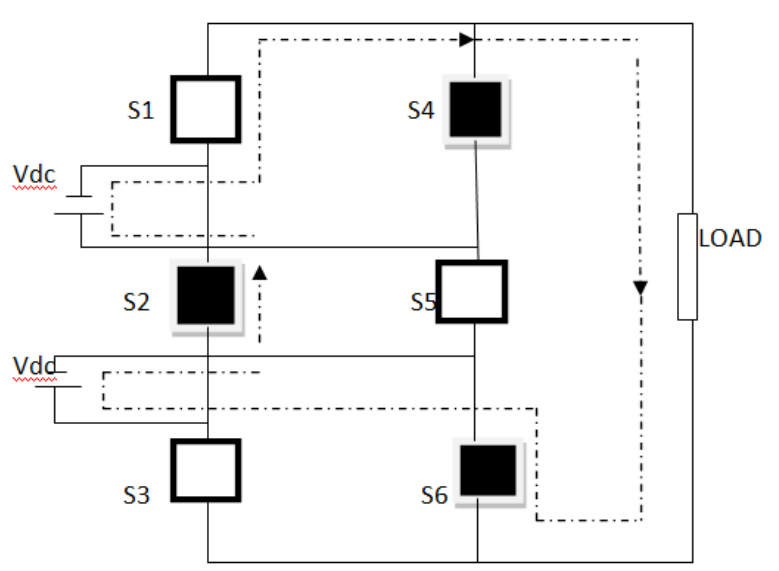

Figure 3: Switching sequences for getting a voltage $+2 \mathrm{Vdc}$.

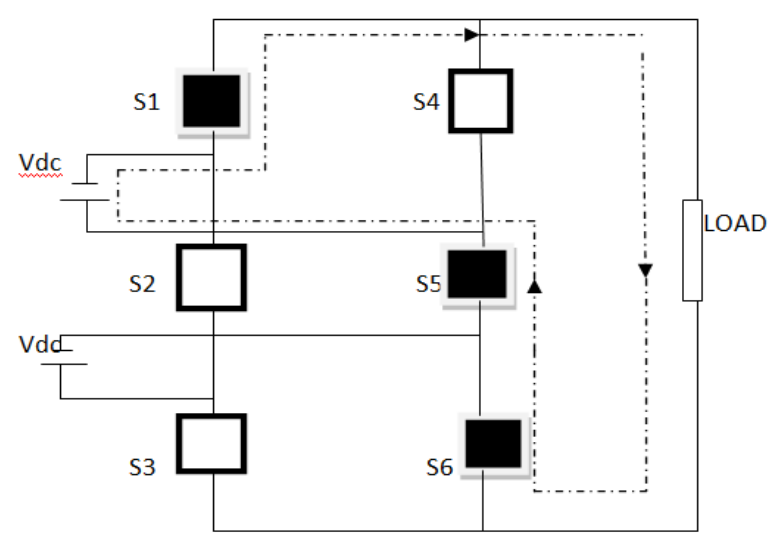

Figure 4: Switching sequence for getting a voltage $+1 \mathrm{Vdc}$. 


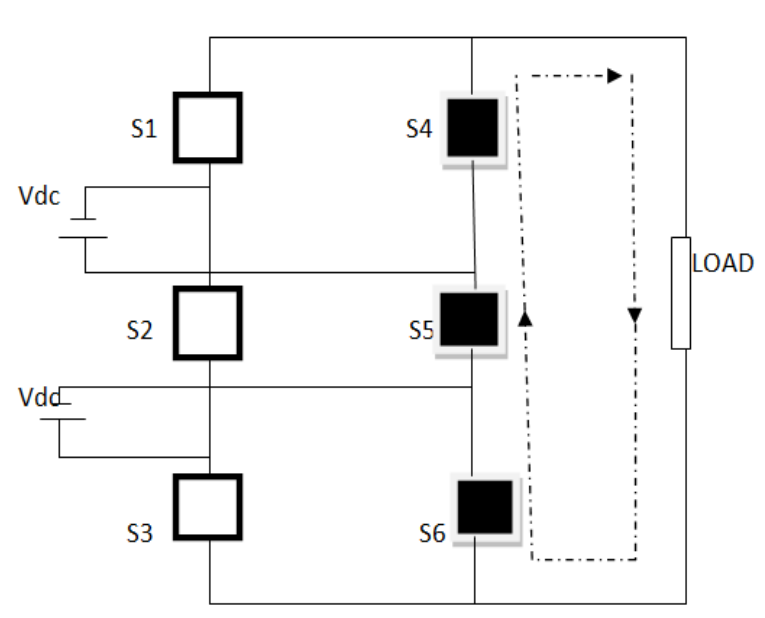

Figure 5: Switching sequence for getting a zero voltage.

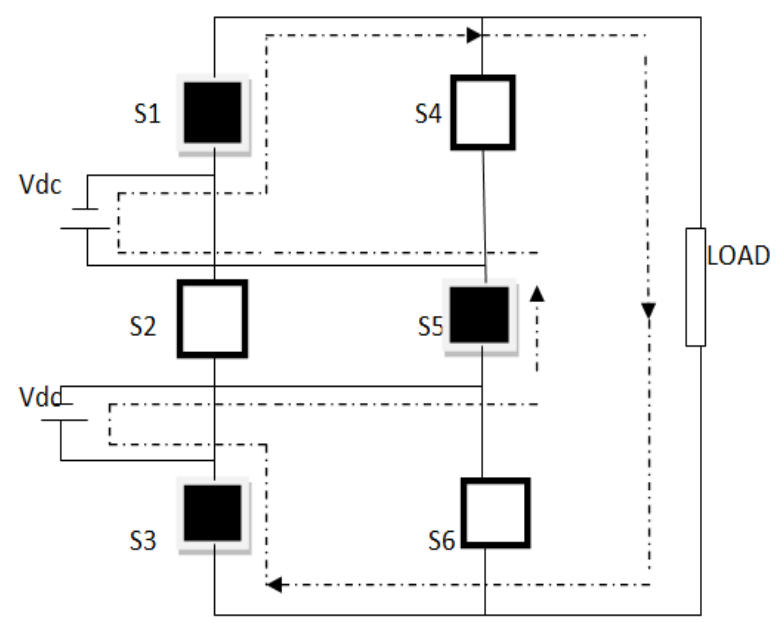

Figure 6: switching sequence for zero voltage.

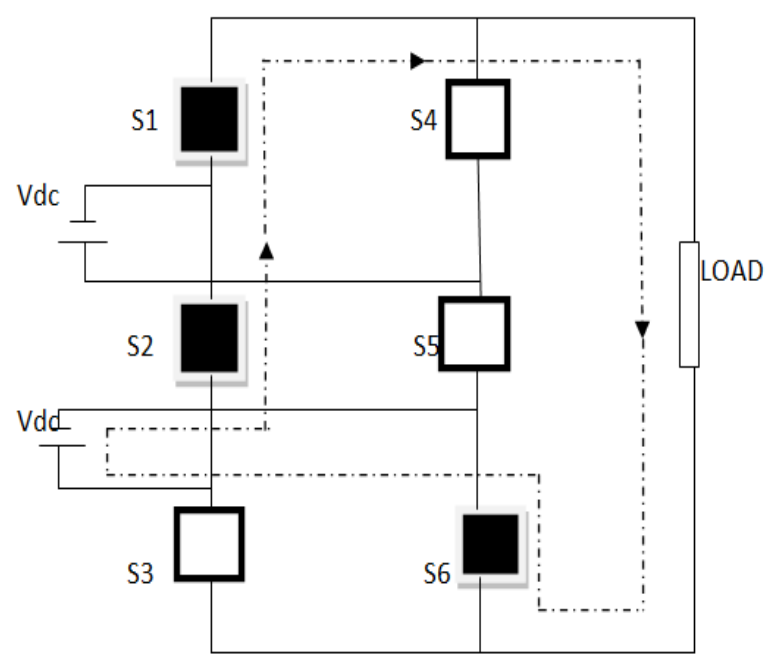

Figure 7: Switching sequence for getting $-1 \mathrm{Vdc}$ voltage.

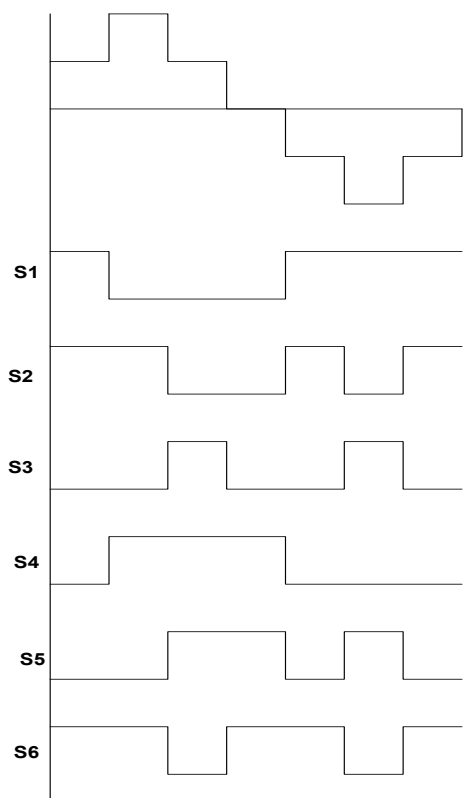

Figure 8: Triggering pulses for five level symmetric $\mathrm{CHB}$ MLI.

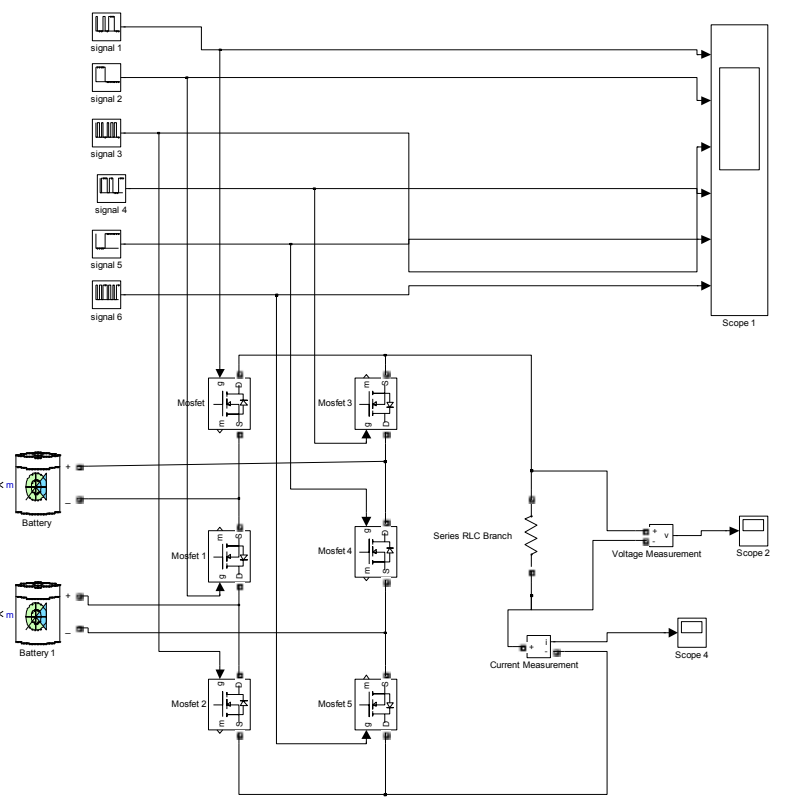

Figure 9: 5-level CHB MLI circuitry in MATLAB tool.

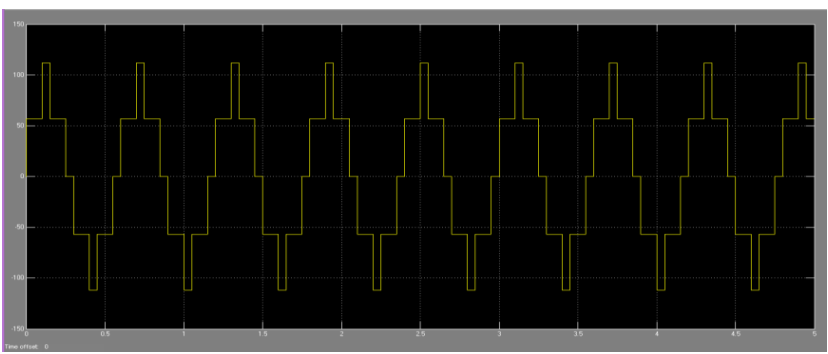

Figure 10: Output waveform of 5-levels single phase symmetric CHB MLI. 

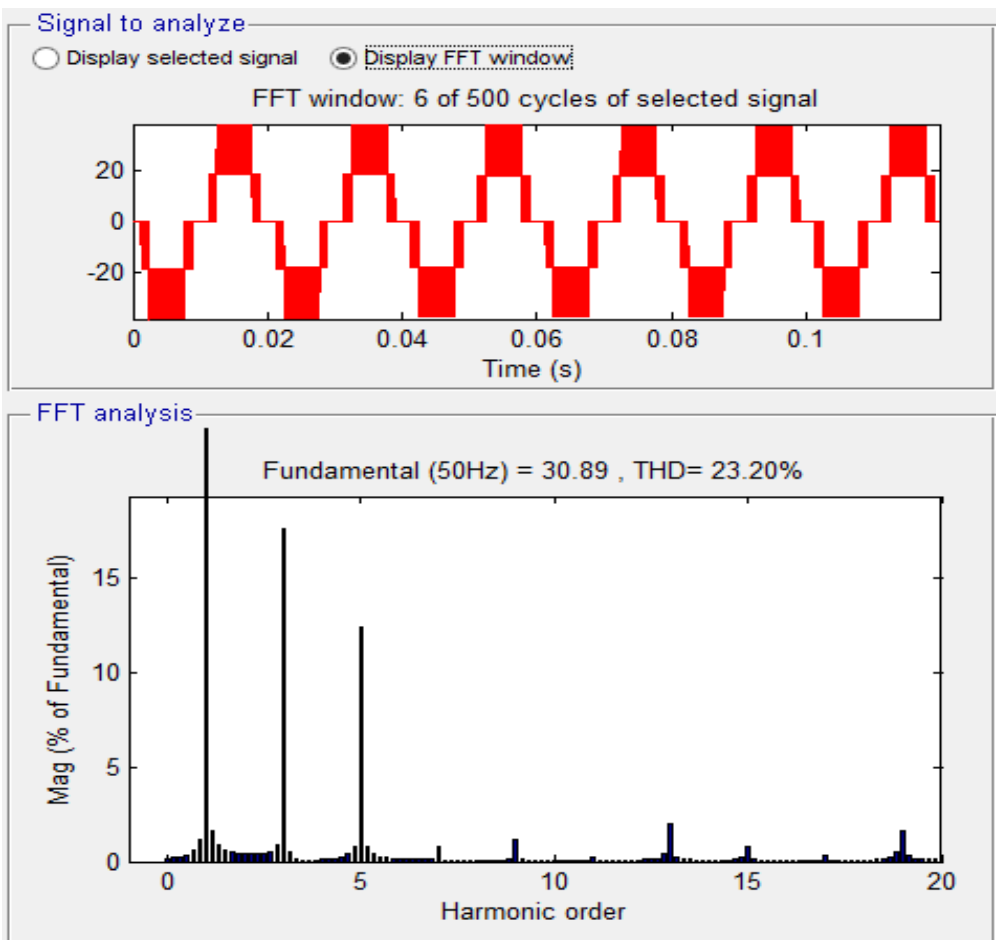

Figure 11: 5-levels THD in MATLAB tool.

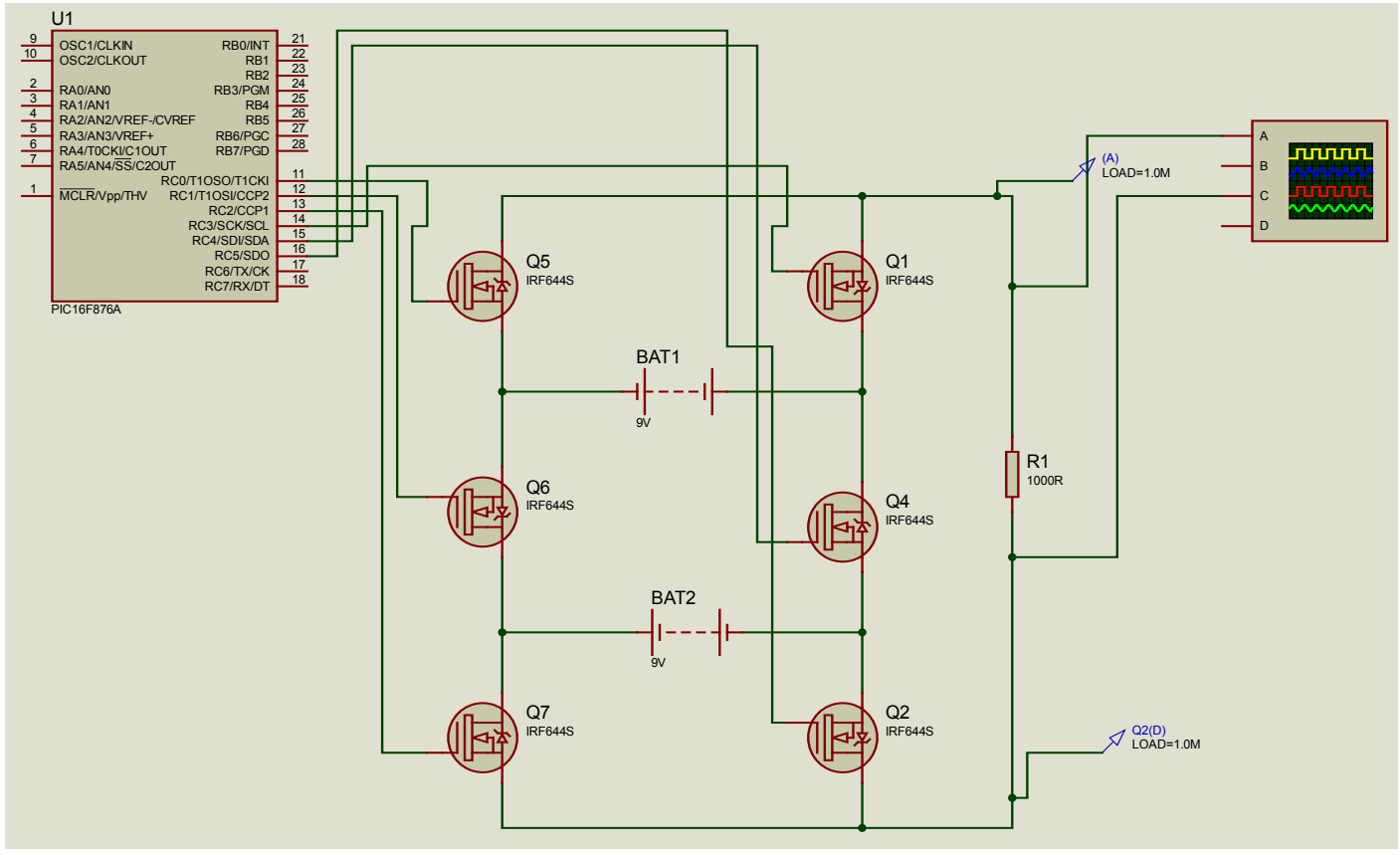

Figure 12: 5-level symmetric CHB MLI circuitry in proteous software.

\section{Conclusion}

This paper showed that this modified multilevel inverter topology with reduced number of switches can be implemented for industrial drive applications. This multilevel inverter structure and its basic operations have been analyzed. A detailed procedure for calculating required voltage level on each stage has been analyzed. As conventional five-level inverter involves eight switches, it increases switching losses; cost and circuit complexity. This 5-level inverter engages only six switches which reduces switching losses, cost and circuit complexity. Moreover it effectively reduces lower order harmonics. Therefore effective reduction of total harmonics distortion is achieved. 
Citation: Adem Y (2018) Design and Simulation of Single-Phase Five-Level Symmetrical Cascaded H-Bridge Multilevel Inverter With Reduces Number of Switches. J Electr Electron Syst 7: 281. doi: 10.4172/2332-0796.1000281

Page 5 of 5

\section{References}

1. http://www.esru.strath.ac.uk

2. Kavita M, Arunkumar A, Gokulnath N, Arun S (2012) New cascaded H-bridge multilevel inverter topology with reduced number of switches and sources. IOSR-JEEE 2: 26-36.

3. Peng FZ, Lai JS (2003) Multilevel converters, A new breed of power Electronics converters. IEEE Trans Ind Appl 32: 509 -517.

4. Rodriguez J, Lai JS, Peng FZ (2003) Multilevel Inverter: A survey topology control and application. IEEE Trans Ind Electro 49: 724-738.

5. Nabae A, Takahashi I, Akagi H (2003) New neutral point clamped pwm inverter. IEEE Trans Ind Appl IA-17: 518-523.

6. Taylor BE (2003) power MOSFET design. Uk.

7. Foch H, Meynard TA (1992) Multilevel conversion; High voltage choppers and voltage sources inverters. IEEE Trans Ind Appl pp: 397-403.

8. Jadin, Bin MS (2008) Power Electronics system and drives DC to AC Converter. Malaysia: university of malaysia pahang.

9. kumar J (2012) THD Analysis for different levels of cascade multilevel inverter for industrials applications. IJETAE 2: 20-30.
10. Ganesan P, Kurup SB, Mohan D, Kalyani D (2003) Performance Analysis of multilevel shunt active filter based on SDM. Digit Signal Process 3: 42-46.

11. Choi NS, Cho JG, Cho GH (1991) A general circuit topology of multilevel inverter. IEEE PESC, pp: 397-403.

12. Yashobanta $P$ (2003) Analysis of cascaded multilevel inverter induction motor drive. E Thesis NIT Rourkela.

13. Gupta R, Gosh A, Joshi A (2008) Switching characterization of cascaded multilevel inverter. IEEE Trans Industr Electron 55: 1047-1058.

14. Kouro S, Rebollello J, Rod J, Rodriguez J (2007) Reduced switching frequency modulation algorithm for high power multilevel inverter. IEEE Trans Industr Electron 54: 2894-2901.

15. Hamilla DC (1994) Review of Power MOSFET Design. By B. E. Taylor, Wiley Chichester, Uk.

16. Uk corporation. May 24, 2003. http//www.esru.strath.ac.uk/

17. Polisetty VAB, Narendra BR (2013) Enhanced performance of multilevel inverter fed induction motor drive. IJAREEIE: 2: 5655-5661. 